\title{
Degradação da fibra de coco imersa em soluções alcalinas de cimento e $\mathrm{NaOH}$
}

\author{
Everton J. da Silva ${ }^{1}$, Maria L. Marques ${ }^{1}$, Fermin G. Velasco ${ }^{2}$, \\ Celso C. M. Fornari Junior ${ }^{2} \&$ Francisco H. M. Luzardo² \\ ${ }^{1}$ Instituo Federal de Educação, Ciência e Tecnologia da Bahia/Campus Eunápolis. Eunápolis, BA. E-mail: js_everton@yahoo.com.br. Bolsista FAPESB \\ (Autor correspondente); lidiane_marques@yahoo.com.br. Bolsista FAPESB \\ ${ }^{2}$ Departamento de Ciências Exatas e Tecnológicas/Universidade Estadual de Santa Cruz. Ilhéus, BA. E-mail: fermingv@gmail.com; celso@uesc.br; \\ fmartinezluzardo@gmail.com
}

\section{Palavras-chave: degradabilidade fibras naturais matriz cimentícia}

\begin{abstract}
R E S U M O
Realizou-se este trabalho com o objetivo de analisar os efeitos que soluções aquosas alcalinas exercem sobre a fibra de coco, em função do tempo. O processo pretende simular, de forma acelerada, as condições de degradação que ocorrem nas fibras de coco inseridas em matrizes cimentícias. As fibras inseridas em soluções alcalinas com diferentes concentrações foram analisadas através de gravimetria, microscopia eletrônica de varredura e espectrometria na região do infravermelho. As soluções foram estudadas através da técnica da medição de absorção por ultravioleta, durante o segundo semestre de 2013. De acordo com o aumento da concentração das soluções e do tempo de contato com as fibras de coco, houve uma modificação maior da superfície da fibra através da retirada dos constituintes superficiais, como cutículas, partículas globulares, cavidades e também lignina.
\end{abstract}

Key words:

degradability

natural fibers

cement matrix

\section{Degradation of coconut fiber immersed in cement and $\mathrm{NaOH}$ alkaline solutions}

\begin{abstract}
A B S T R A C T
This paper aims to analyse the effects of alkaline aqueous solutions on coconut fiber as a function of time. The process intended to simulate the conditions of degradation that occurs in the coconut fibers embedded in cementitious matrix. The fibers inserted in alkaline solutions with different concentrations were analysed by gravimetric, scanning electron microscopy and Fourier Transform Infrared spectroscopy (FTIR) methods. Alternative solutions have been studied by the technique of measuring UV-vis spectroscopy, during the second half of 2013. According to the increasing concentration of solutions and the time of contact with coconut fibers, a greater fiber surface modification occurred, by removal of surface constituents, such as cuticles, globular particles, pits and also lignin.
\end{abstract}




\section{INTRODUÇÃo}

As fibras naturais existem em abundância e têm seu uso motivado por serem renováveis e pela sua disponibilidade a baixo custo. Muitas vezes como resíduos e sem uma destinação específica, as fibras acabam se transformando em problemas de ordem ambiental. Cabe aos pesquisadores a responsabilidade de encontrar soluções viáveis do ponto de vista econômico e ambiental, assim como eficazes para aplicações tecnológicas.

No Brasil, a produção de coco é uma das culturas de maior destaque referente à geração de quantidade de resíduos de fibra vegetal. De acordo com o IBGE (2015), a produção de coco no Brasil alcançará 1.909.705 toneladas na safra 2015. Esta grande quantidade de coco propicia a oferta para a utilização de suas fibras para diversas finalidades dentre elas a incorporação (através de adição) em matrizes de cimento Portland, a qual permite melhorar a resistência à tração e o conforto térmico da argamassa com a diminuição de custo do material.

$\mathrm{O}$ assunto despertou o interesse da comunidade científica e vem sendo objeto de diversas pesquisas recentes, como: Gunasekaran et al. (2011), Rodríguez et al. (2011), Ali et al. (2012; 2013), Silva et al. (2012), e Ramli et al. (2013). Esses trabalhos apontam que sua aplicação pode melhorar diversas propriedades físicas e mecânicas de compósitos cimentícios; no entanto, um dos aspectos mais importantes a respeito desta aplicação está associado à durabilidade da fibra de coco no interior da matriz cimentícia. $\mathrm{O}$ ambiente alcalino, provocado pelos produtos gerados na fase de hidratação do cimento, como o hidróxido de cálcio e silicatos/aluminatos de cálcio hidratados, pode interagir com os constituintes da fibra de coco resultando em uma degradação considerável.

Toledo Filho et al. (1997) apontam que pode ocorrer fragilização da fibra pelo processo de mineralização, resultante da migração de produtos de hidratação, especialmente o hidróxido de cálcio, para a cavidade central, paredes e vazios da fibra, onde cristalizam, o que é passível de provocar a ruptura sem o alongamento adequado contribuindo para a perda de qualidade das propriedades do compósito cimentício.

Agopyan \& Savastano Júnior (2003) alertam que a formação de grandes cristais de portlandita (hidróxido de cálcio) pode induzir a decomposição das fibras vegetais em especial sua fração de lignina, com a consequente perda de capacidade de reforço, sobremaneira nas idades mais avançadas em virtude da elevada alcalinidade da água presente nos poros da matriz de cimento Portland.

Uma pesquisa na qual se observou a durabilidade de matrizes cimentícias com fibra de coco comparou fibras novas com fibras presentes em uma argamassa utilizada em uma parede construída há 12 anos. Neste trabalho Jhon et al. (2005) concluíram que as amostras de fibra extraídas da parede continham um teor menor de lignina em comparação com as fibras novas; além disto também se observou que a amostra da parede externa, exposta a ciclos de umedecimento e secagem, também apresentou menor teor de lignina que a amostra da parede interna. Ambos os resultados indicaram que a lignina teria sido degradada.
A partir dessas pesquisas verifica-se que é necessário um tempo para a fibra de coco ser afetada pelo ambiente alcalino e sua consequente degradação. Neste sentido o presente trabalho tem por objetivo analisar os efeitos que soluções aquosas alcalinas exercem sobre a fibra de coco. O estudo foi realizado em condições laboratoriais, visando simular, de forma acelerada, o ambiente físico-químico de degradação a que estão submetidas as fibras dentro da matriz cimentícia.

\section{Material e Métodos}

As amostras foram preparadas através da distribuição de um conjunto de 10 fibras de coco totalmente naturais, sem quaisquer pré-tratamentos, de espessura constante e comprimento de $25 \mathrm{~mm}$, conforme recomendação de Silva et al. (2014). As fibras foram secadas pelo período de $2 \mathrm{~h} \mathrm{em}$ estufa a $102+/$ - 2 graus Celsius (modelo MD 1.3 Medicate) até sua pesagem constante; posteriormente foi realizada a pesagem inicial (balança analítica de alta precisão até $10^{-4} \mathrm{~g}$ ) de cada amostra formada pelo conjunto das 10 fibras secas com $25 \mathrm{~mm}$.

As soluções (nas quais as amostras seriam imersas) foram preparadas com Cimento Portland CP V ARI, água deionizada por troca iônica e Hidróxido de Sódio P. A., conforme proporções descritas na Tabela 1 . A sequência de produção das soluções foi: primeiro a água, depois o conjunto de 10 fibras e, por último, o cimento ou hidróxido de sódio. Foi utilizado o pHetro de bancada $\mathrm{pH} 250$ policontrol para a avaliação do $\mathrm{pH}$ das soluções.

As fibras foram colocadas nas soluções e retiradas semanalmente, para análise. Para isto, foram lavadas em ultrassom (modelo ultraclaner 1400) por $10 \mathrm{~min}$, enxaguadas com água deionizada e secadas em estufa a $102+/-2^{\circ} \mathrm{C}$ por 2 $h$, até sua pesagem constante; posteriormente, foram colocadas no dessecador por $10 \mathrm{~min}$, até sua pesagem constante, para análise gravimétrica.

Após a pesagem (realizada a cada 7 dias), cada amostra de fibra foi devolvida à sua respectiva solução para a continuação do ensaio de gravimetria, que foi desenvolvido até 81 dias. As fibras degradadas foram estudadas através de microscopia óptica (modelo Tecnival SQF-F), microscopia eletrônica de varredura (MEV - modelo Quanta 250) e espectrometria na região do infravermelho (FTIR - modelo thermo scientific nicolet i S10). As soluções de onde as fibras foram retiradas foram estudadas através da técnica da medição de absorção por ultravioleta (UV - modelo Bioespectro SP-220). A pesquisa foi desenvolvida na Universidade Estadual de Santa Cruz, BA, durante o segundo semestre de 2013.

Tabela 1. Composição das soluções para imersão das fibras de coco

\begin{tabular}{cccc}
\hline \multirow{2}{*}{ Amostra } & Cimento & Hidróxido de sódio & Água \\
\cline { 2 - 4 } & & $\mathbf{( g )}$ & \\
Água 60 & - & - & 60 \\
Cimento 15 & 15 & - & 45 \\
$\mathrm{NaOH} 01$ & - & 01 & 59 \\
$\mathrm{NaOH} 10$ & - & 10 & 50 \\
$\mathrm{NaOH} 20$ & - & 20 & 40 \\
\hline
\end{tabular}




\section{Resultados E Discussão}

A superfície das fibras de coco geralmente apresenta substâncias e relevos particulares para este tipo de fibra. Saw et al. (2011) demonstram que na superfície da fibra existem cavidades, partículas globulares e cutículas (camadas de cera ou gordura), que se apresentam como finas coberturas que encobrem sua estrutura.

Esta condição pode ser modificada pela presença de umidade; por exemplo, quando a água entra em contato com as fibras se interpõe entre a estrutura principal e as cutículas tendo como consequência o deslocamento dessas camadas. As amostras de fibras de coco que foram avaliadas pela técnica de gravimetria demonstraram que, ao final do ensaio, ocorreu perda de massa em todos os tipos de amostras.

A variação percentual de massa da fibra, com referência à sua massa original, é mostrada na Figura 1.

Observa-se que as fibras colocadas em água pura (Água60), obtiveram a menor variação de massa em relação às demais amostras, com uma perda de massa correspondente a $6,98 \%$. Esta variação pode ser atribuída à perda de pequenas incrustações contidas originalmente na superfície da fibra de coco e que constituem as camadas de cutículas (Nam et al., 2011). Possivelmente foram deslocadas da superfície da fibra para a solução em que a mesma estava imersa.

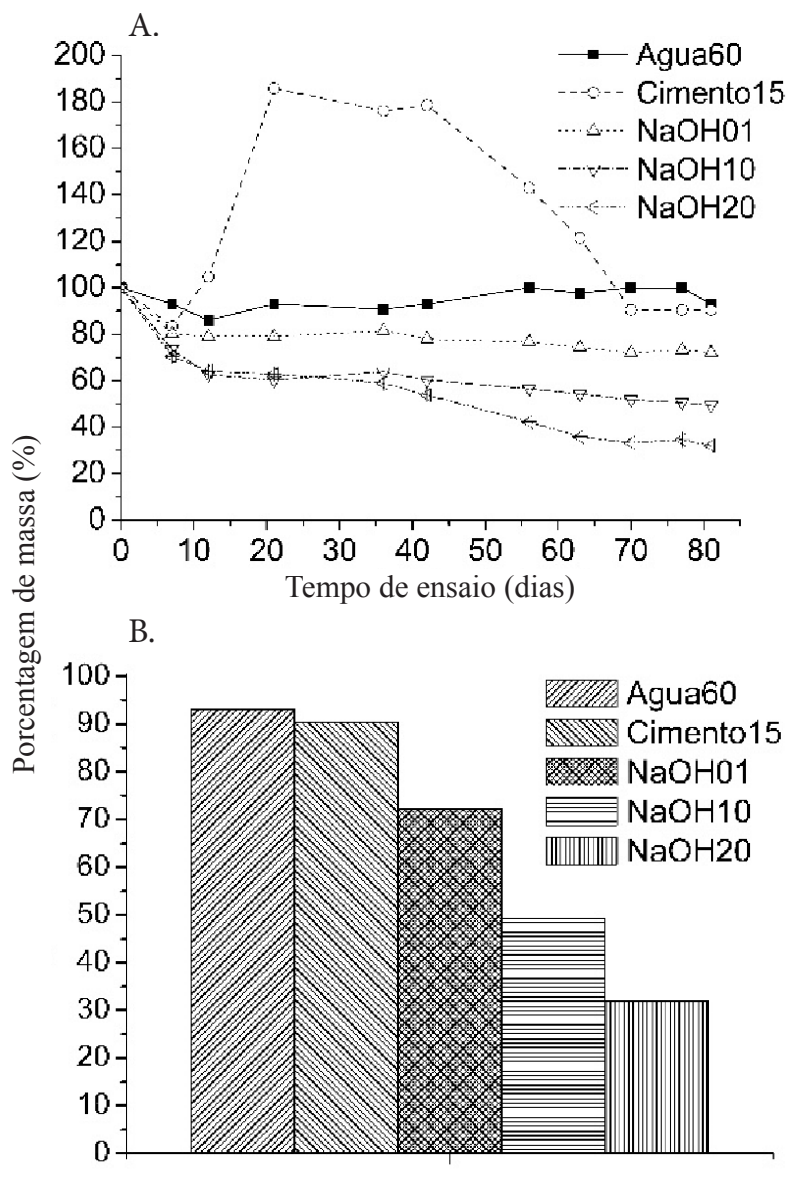

81 dias de ensaio

Figura 1. Percentual de massa das fibras de coco com referência à massa original: em função do tempo a que foram submetidas a diferentes tipos de soluções (A); percentual de massa final de cada amostra de fibra de Coco (B)
Para o caso das fibras colocadas na solução com cimento (Cimento-15), entre a segunda e oitava semana, nota-se um aumento significativo de massa em relação à massa inicial; por exemplo, no dia 21 do experimento chegou-se a $85,7 \%$. De acordo com Savastano Júnior \& Agopyan (1999), isto pode ser atribuído aos cristais de hidróxido de cálcio formados no processo de hidratação do cimento, que ficam aderidos nas paredes das fibras e mesmo após os procedimentos de lavagem e secagem, eles permaneceram aderidos à fibra de coco. Esses cristais podem ser vistos nas Figuras 2A e 2B.

Após aproximadamente 60 dias de exposição foi observada, entretanto, uma queda de massa das fibras da amostra Cimento-15; ocorreu que, após este período, os cristais de hidróxido de cálcio se soltaram das fibras provavelmente pela ação do ultrassom e pelo processo de degradação de parte dos constituintes da fibra de coco.

O comportamento de ganho de massa, que ocorreu durante as primeiras semanas para as amostras acondicionadas na solução Cimento-15, não foi observado para as fibras colocadas nas soluções com hidróxido de sódio e água pura. As três soluções de hidróxido de sódio e a solução de água pura estudadas provocaram perda de massa em suas fibras de coco, desde os primeiros dias de imersão.

Em referência à variação de massa final das amostras de fibra de coco (Figura 1B), a amostra imersa na solução Cimento-15 diminuiu 9,52\%. A diminuição da massa das amostras de fibra de coco aumentou com a concentração e hidróxido de sódio da solução. A amostra com maior concentração de hidróxido de sódio $(\mathrm{NaOH}-20)$ promoveu a maior degradação das fibras chegando a uma perda de massa (em relação à massa inicial) de $67,95 \%$, contra $50,60 \%$ da amostra $\mathrm{NaOH}-10$ e $27,91 \%$ da amostra NaOH-01.

Ramakrishna \& Sundararajan (2005) investigaram a variação da composição química e da resistência à tração da fibra de coco e outras fibras naturais. Foram utilizados três meios de imersão das fibras: água pura, água saturada de cal e hidróxido de sódio. Os autores concluíram que a solução de hidróxido de sódio promove a maior alteração da composição química e também a maior perda de resistência a tração dentre os meios estudados. Em outro trabalho na mesma direção, $\mathrm{Gu}$ (2009) tratou fibras de coco com soluções de $\mathrm{NaOH}$ cuja concentração variou de 2 a $10 \%$, por quatro semanas. O autor detectou tendência de diminuição da resistência à tração das fibras de coco de acordo com o aumento da concentração de $\mathrm{NaOH}$.

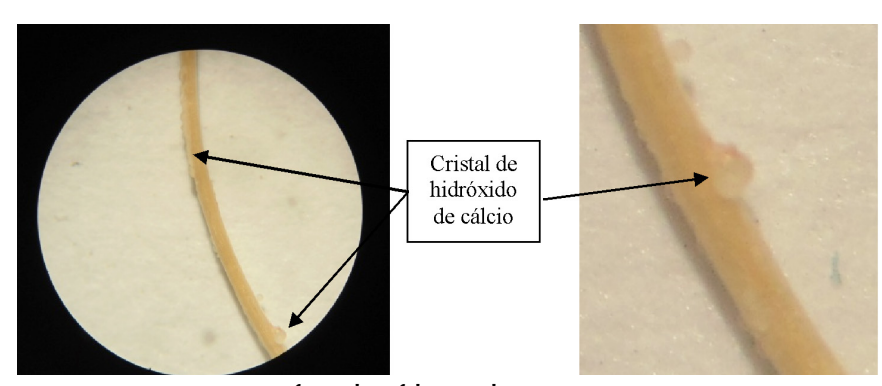

Figura 2. Fotografia da fibra de coco por microscopia óptica após 36 dias em solução com cimento (A); detalhe do cristal de hidróxido de cálcio aderido na superfície da fibra (B) 
Espera-se que a maior perda de massa (maior grau de degradação) verificada nas amostras NaOH-10 e NaOH-20 do presente trabalho, possa estar associada à redução de resistência à tração em função do aumento da porcentagem de $\mathrm{NaOH}$ constatada por Ramakrishna \& Sundararajan (2005) e Gu (2009).

As imagens das fibras obtidas por MEV, foram realizadas ao término do ensaio de gravimetria. O tempo de exposição maior que 81 dias, em medidas consecutivas, mostrou variações de massa muito pequenas.

Analisando a Figura 3 observa-se que existem pequenas irregularidades na superfície da fibra de coco cujas camadas de cutículas revestem a fibra com uma cobertura em formato de couraça e as partículas globulares se apresentam como saliências fixadas em cavidades específicas da própria fibra. Essas irregularidades são "promoções" externas (cutículas e partículas globulares) que se instalam na superfície das fibras e propiciam uma morfologia irregular.

Na Figura 4 pode-se perceber que o contato com a água promoveu a retirada de parte da camada de cutícula da fibra de coco, formando uma morfologia mais lisa e regular na sua superfície, porém as partículas globulares permaneceram fixadas às suas respectivas cavidades demonstrando que a ação da água não foi suficiente para a remoção dessas irregularidades.

Por outro lado, observa-se que grande parte das cavidades superficiais da fibra de coco imersa na solução Cimento-15 (Figura 5) não contém mais as partículas globulares. A presença do cimento na solução promoveu o aumento do $\mathrm{pH}$ da solução para aproximadamente $13 \mathrm{em}$ virtude da formação e reação dos produtos básicos de hidratação do cimento como, por exemplo, o hidróxido de cálcio. Esta alteração das condições químicas da solução associada à presença de água, além de promover a retirada da camada de cutícula também contribuiu para a eliminação das partículas globulares deixando em evidência as cavidades.

Toledo Filho et al. (2000) avaliaram a durabilidade de fibras de coco expostas a soluções alcalinas de hidróxido de cálcio $\mathrm{pH} 12$ e constataram que as fibras perderam completamente sua resistência depois de 300 dias. Segundo os autores, a fragilização das fibras pode ser associada principalmente com a sua mineralização devido à migração de produtos de hidratação para o interior da fibra, em especial o hidróxido de cálcio. A partir disso sugere-se que a ausência de cristais na superfície da fibra, após os 81 dias de acondicionamento em solução, possa ser atribuída ao processo de lavagem das fibras com ultrassom.

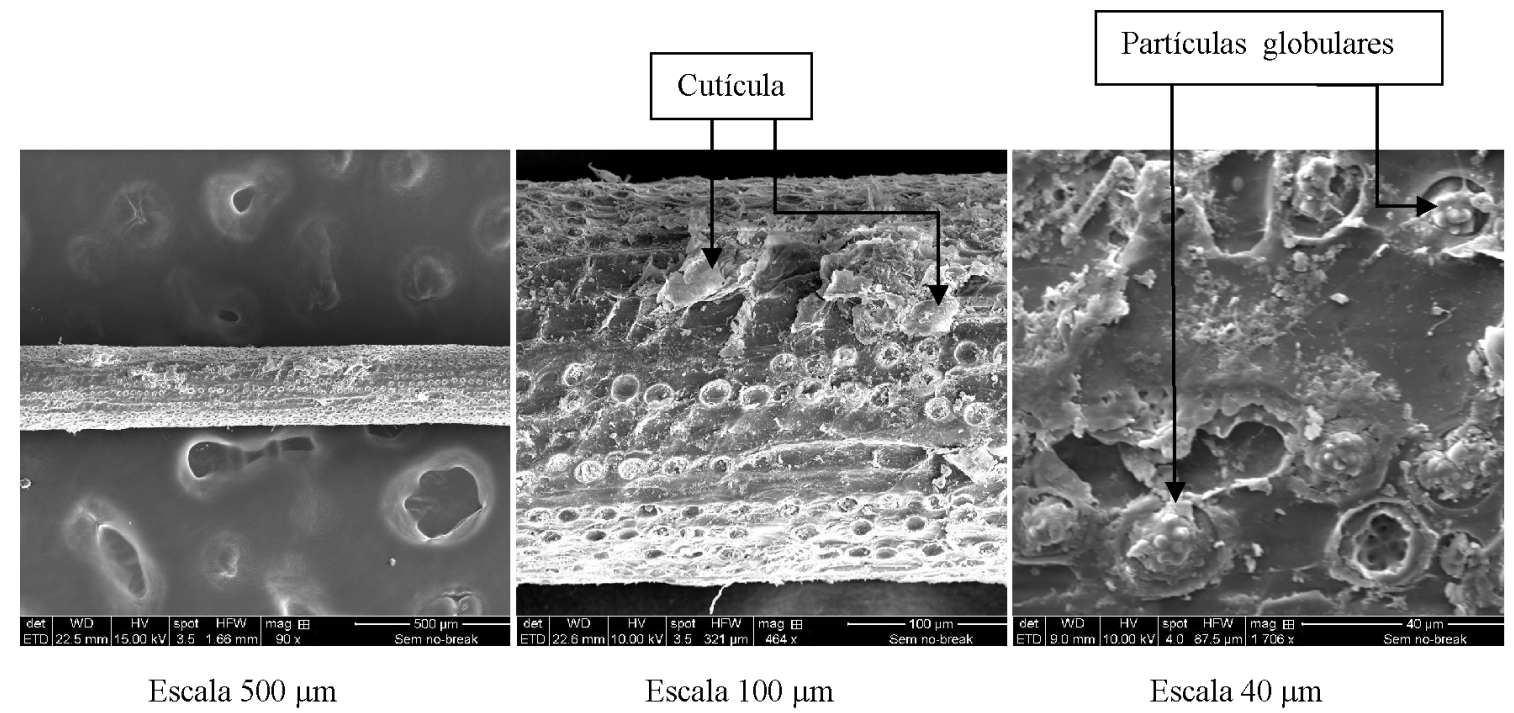

Figura 3. Fotomicrografias em diferentes aumentos por microscopia eletrônica de varredura (MEV) da fibra de coco natural - sem tratamento

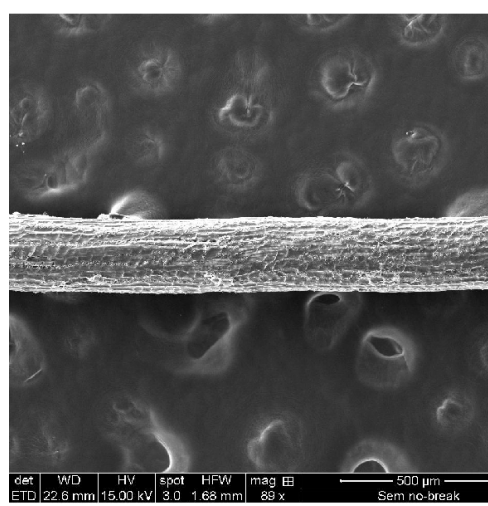

Escala $500 \mu \mathrm{m}$

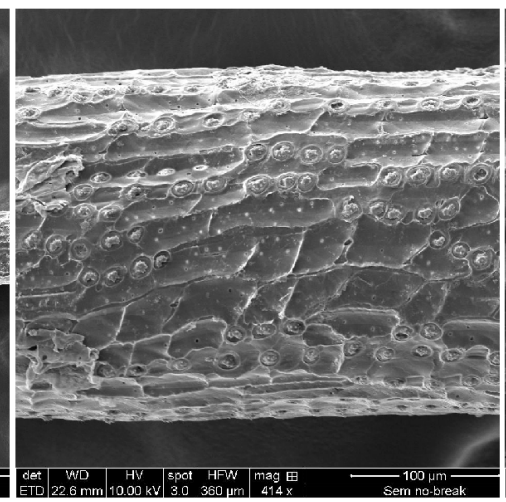

Escala $100 \mu \mathrm{m}$

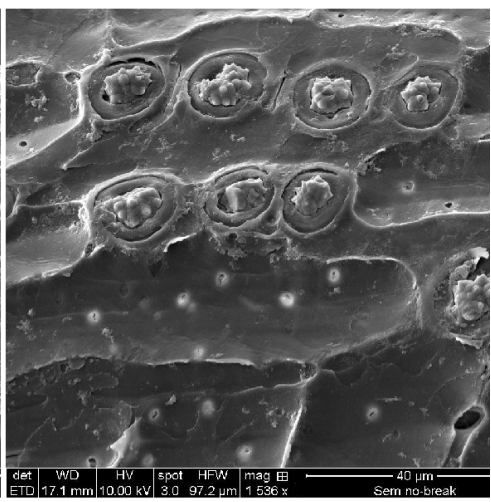

Escala $40 \mu \mathrm{m}$

Figura 4. Fotomicrografias em diferentes aumentos por microscopia eletrônica de varredura (MEV) da fibra de coco imersa por 81 dias na solução Água-60 


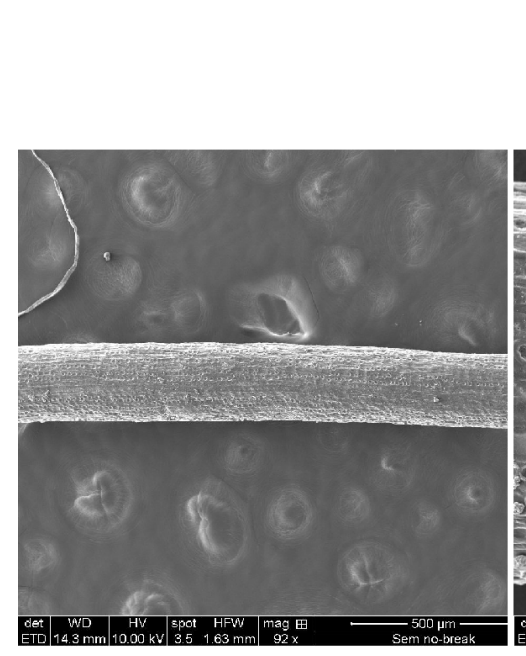

Escala $500 \mu \mathrm{m}$

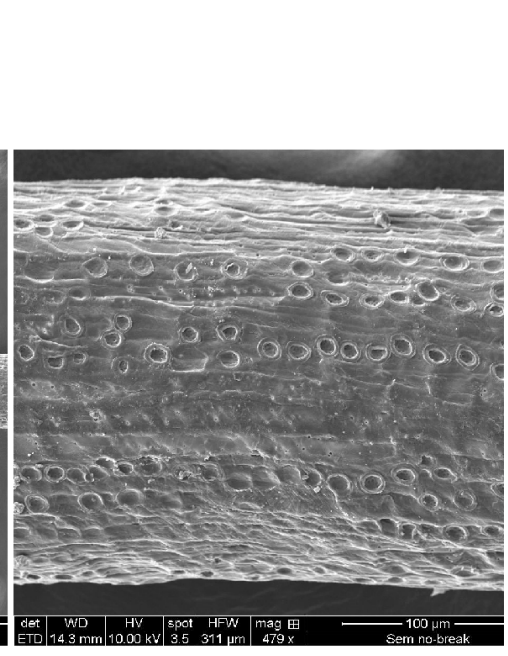

Escala $100 \mu \mathrm{m}$

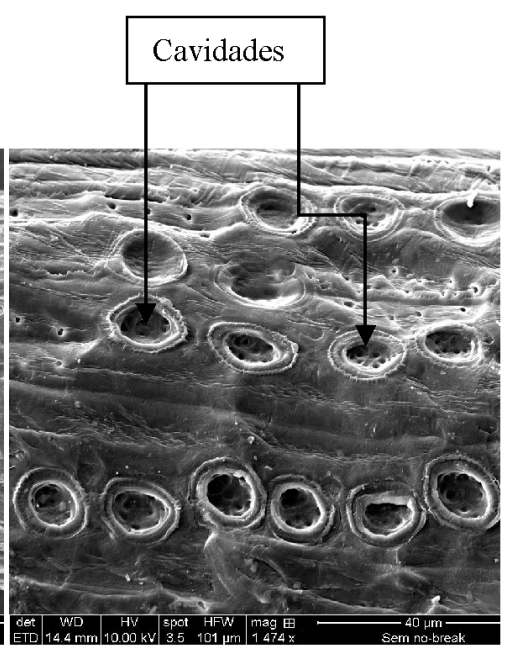

Escala $40 \mu \mathrm{m}$

Figura 5. Fotomicrografias em diferentes aumentos por microscopia eletrônica de varredura (MEV) da fibra de coco imersa por 81 dias na solução Cimento-15

A Figura 6 apresenta os efeitos da exposição da fibra de coco em solução de hidróxido de sódio (NaOH-01). Verificase, por MEV, que a degradação superficial da fibra é bastante significativa e maior que na solução com a presença do cimento; contudo, o resultado de perda de massa após 81 dias em solução alcalina 01 e em cimento mostrou-se semelhante; condição em que a degradação mostra que atingiu a estrutura fibrosa separando as microfibras celulósicas muito provavelmente como consequência da reação entre a lignina da fibra de coco e a solução de $\mathrm{NaOH}$, também observado por Salmah et al. (2013). Na figura não é possível mais distinguir a presença da camada de cutícula, das partículas globulares nem das cavidades onde se encontravam as partículas globulares.

O processo de degradação da superfície da fibra, apresentado na Figura 7, mostrou-se mais intenso e as microfibras resultaram em uma condição de maior afastamento. Este resultado evidencia que uma concentração maior de $\mathrm{NaOH}$ promove uma degradação também maior da lignina, através da reação de hidrólise básica (Albinante et al., 2013).

$\mathrm{Na}$ Figura 8 se observam as amostras de fibras de coco colocadas em solução de hidróxido de sódio e água ( $\mathrm{NaOH}-20)$; nesta condição a fibra de coco está em processo de desfibrilação e ruptura da microfibra em que os vazios deixados pela lignina são tão pronunciados que as microfibras começam a se separar individualmente. Considerando que até $48 \%$ da fibra de coco são compostos por lignina (Albinante et al., 2013), os danos causados pelos tratamentos com hidróxido de sódio podem ser significativos para as fibras de coco. A este respeito outros autores, como Li et al. (2007), afirmam que o $\mathrm{NaOH}$ remove a lignina, cera e óleos que cobrem a superfície externa da parede celular da fibra e despolimeriza a celulose.

Foram realizadas análises de espectrometria UV (Figura 9) com amostras das soluções sem as fibras de coco, após imersão durante os 81 dias de ensaio. Na absorção correspondente à solução de água pura (Água-60), não se verifica pico de absorção, caracterizando a ausência de agrupamentos característicos da lignina. O pico que aparece próximo a 270 $n m$ está relacionado com a presença dos agrupamentos guaiacil e sirigil da macromolécula lignina, conforme Saw et al. (2011).

Ainda em relação à solução Água-60, assim como a gravimetria não indicou grande variação de massa das fibras e a microscopia eletrônica por varredura não mostrou degradação, o ultravioleta não detectou componentes provenientes da fibra. Na curva da solução com cimento observa-se uma absorção superior à observada na amostra Água-60; entretanto bastante discreta comparada às soluções de hidróxido de sódio. Este resultado indica que a água não exerce influência suficiente para extrair ou retirar substâncias provenientes da fibra.

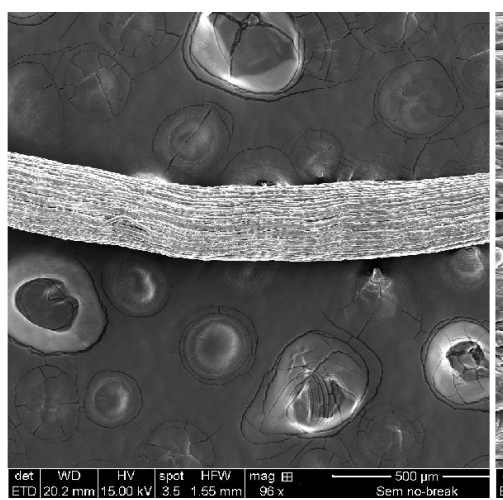

Escala $500 \mu \mathrm{m}$

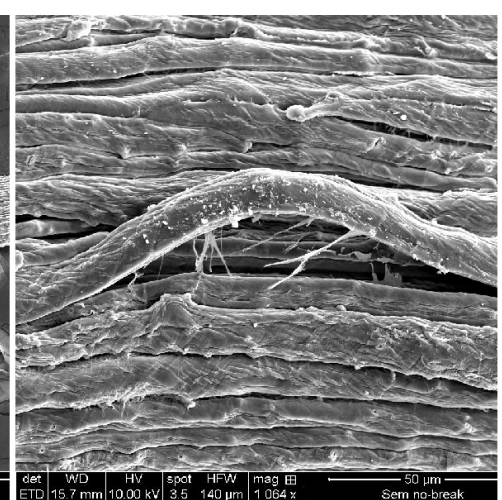

Escala $100 \mu \mathrm{m}$

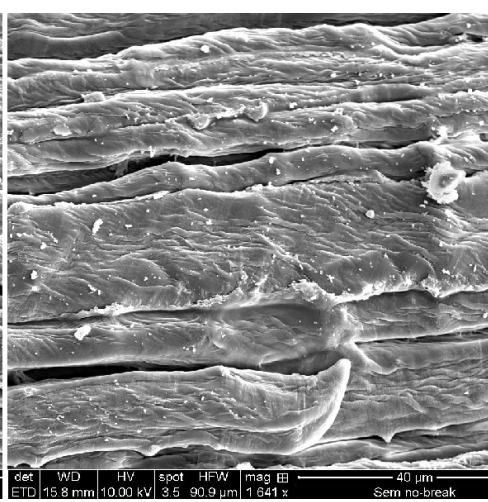

Escala $40 \mu \mathrm{m}$

Figura 6. Fotomicrografias em diferentes aumentos por microscopia eletrônica de varredura (MEV) da fibra de coco imersa por 81 dias na solução $\mathrm{NaOH}-01$ 


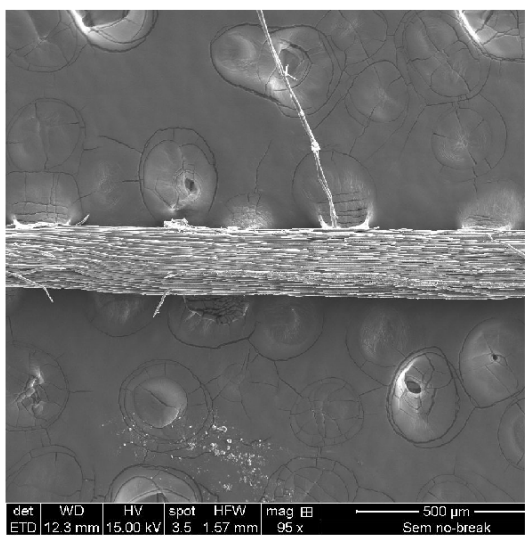

Escala $500 \mu \mathrm{m}$

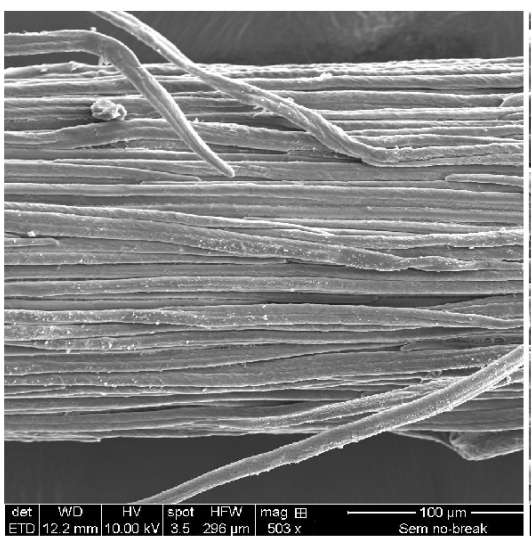

Escala $100 \mu \mathrm{m}$

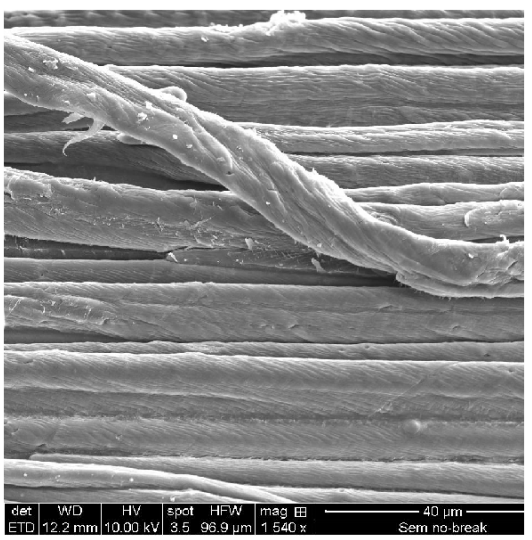

Escala $40 \mu \mathrm{m}$

Figura 7. Fotomicrografias em diferentes aumentos por MEV da fibra de coco imersa por 81 dias na solução $\mathrm{NaOH}-10$

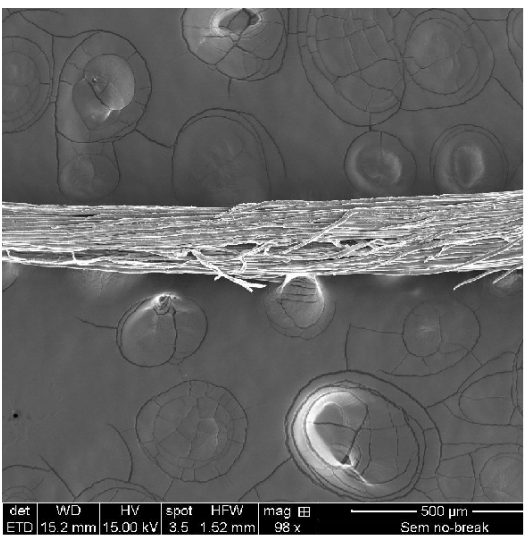

Escala $500 \mu \mathrm{m}$

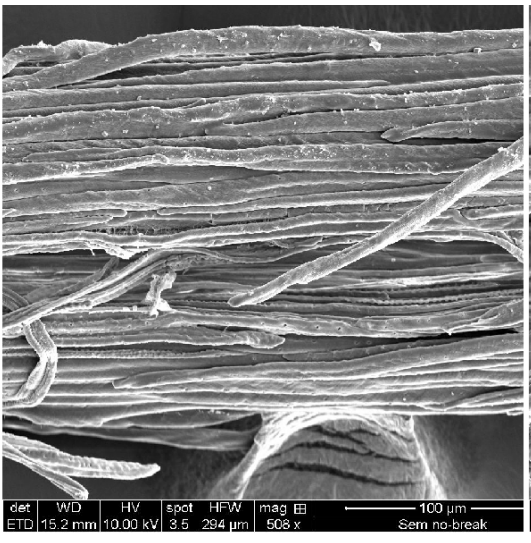

Escala $100 \mu \mathrm{m}$

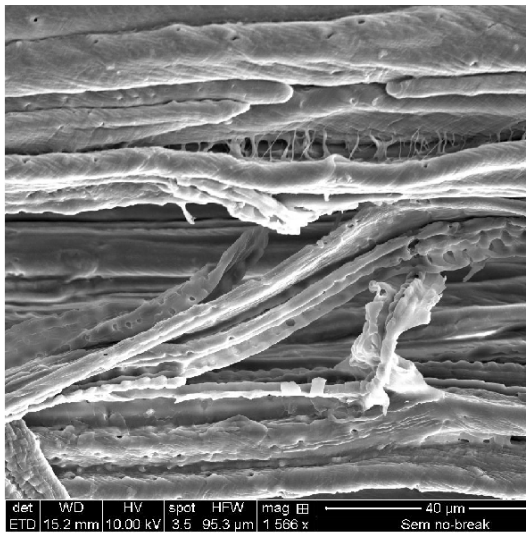

Escala $40 \mu \mathrm{m}$

Figura 8. Fotomicrografias em diferentes aumentos por MEV da fibra de coco imersa por 81 dias na solução NaOH-20

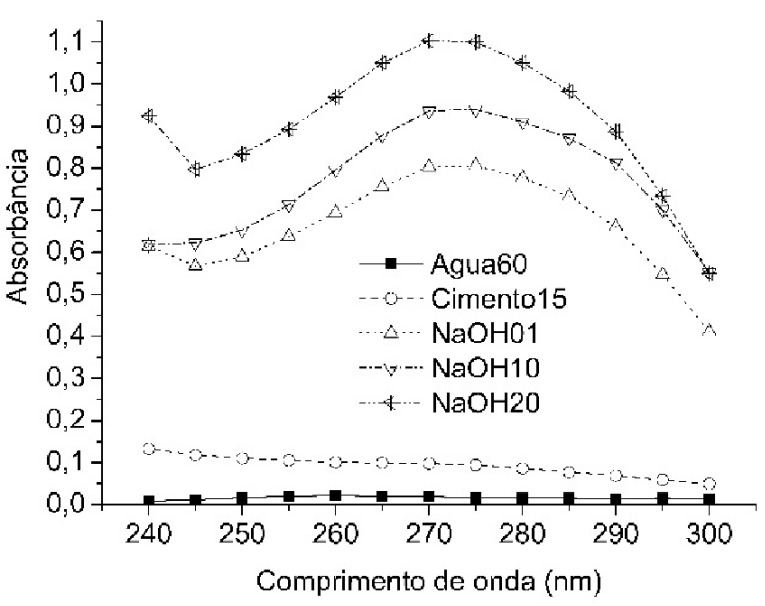

Figura 9. Resultado do ensaio de Ultravioleta para as soluções (Água-60, Cimento-15, NaOH-01, $\mathrm{NaOH}-10$ e $\mathrm{NaOH}-20)$ após retirada das fibras com 81 dias de ensaio

Quanto às curvas das soluções com $\mathrm{NaOH}$, é possível visualizar, em ordem crescente, que quanto maior foi a concentração alcalina mais componentes foram absorvidos no ensaio, ou seja, maior foi a degradação das fibras de coco. É possível que esta absorção esteja relacionada à presença de polifenois de taninos condensados (Luzardo et al., 2015).

Da mesma forma como o ensaio gravimetria indicou maior perda de massa e a microscopia apontou desfibrilação, o ultravioleta mostrou que a solução $\mathrm{NaOH}-20$ apresentou a maior concentração de componentes presentes na solução.
Ao analisar os espectros FTIR das fibras de coco retiradas das soluções alcalinas (Figura 10), é possível estabelecer algumas relações entre as diversas bandas e como elas se apresentam em cada espectro.

A banda $\approx 3420 \mathrm{~cm}^{-1}$ indica vibrações dos grupos $\mathrm{OH}$ e ligações $\mathrm{H}$ (Esmeraldo et al, 2010) em polímeros de lignina e polifenois. Esses picos foram observados em todos os espectros; já a banda $\approx 2928 \mathrm{~cm}^{-1}$ indica vibrações de ligações $\mathrm{C}-\mathrm{H}$ $\left(\mathrm{Csp}_{3}-\mathrm{H}\right)$ próprias de ácidos carboxílicos de fenois. Esses picos também foram observados em todas as análises.

Os presentes autores concordam com Ramírez (2011), no sentido de que a banda $\approx 1735 \mathrm{~cm}^{-1}$ corresponde a vibrações do grupo carbonila de ácidos carboxílicos aromáticos conjugados. É possível concluir que a não presença deste grupo químico nas amostras imersas em solução de $\mathrm{NaOH}$, corresponde a uma perda do grupo carbonila devido à hidrólise da lignina em meio alcalino, com a ocorrência do processo de descarboxilação. As Figuras 10A e 10B apresentaram esta vibração. Os comportamentos dos espectros FTIR dessas amostras estão correspondentes às visualizações verificadas nas imagens obtidas através do MEV, visto que essas amostras não apresentaram sinais de degradação da superfície da fibra; além disto, o desvio da linha de base no espectro UV foi o menos pronunciado para essas amostras.

Bandas $\approx 1653 \mathrm{~cm}^{-1} \mathrm{e} \approx 1609 \mathrm{~cm}^{-1}$ indicam a existência de vibrações de ligação $\mathrm{C}$-C conjugadas (de núcleo aromático) que estão relacionadas com estruturas fenólicas da lignina. 

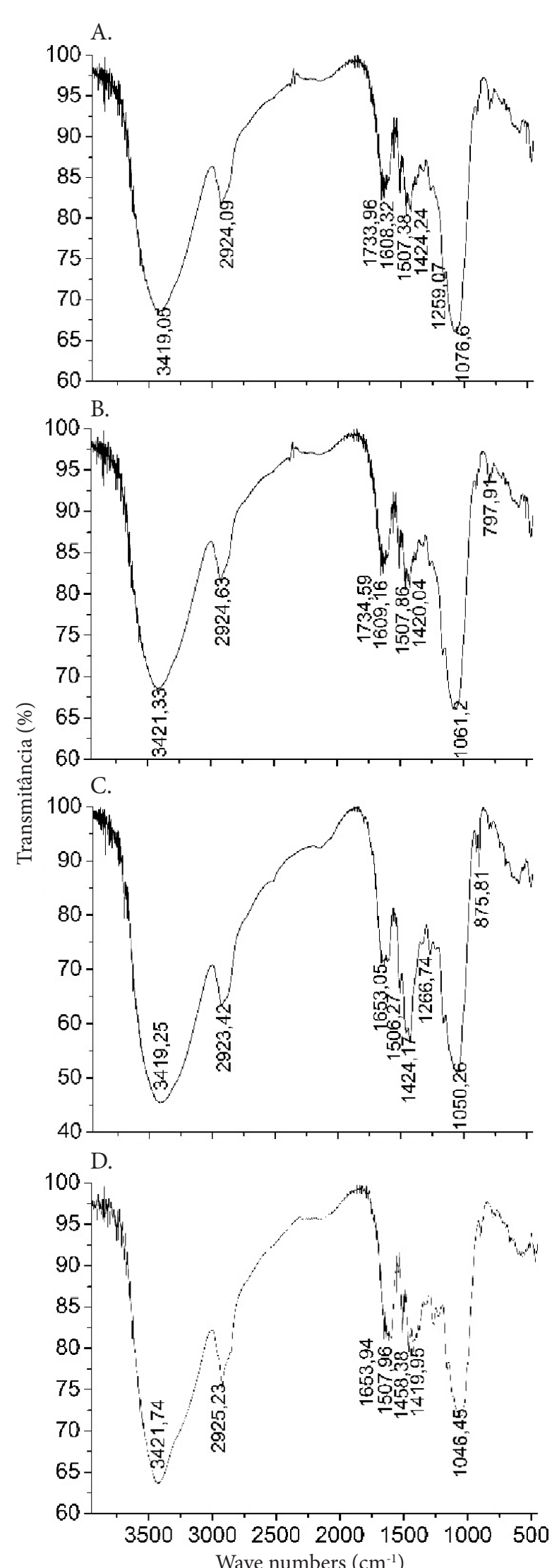

Figura 10. FTIR das amostras de fibras de coco após 81 dias de imersão em: Água-60 (A), Cimento-15 (B), NaOH-01 (C) e $\mathrm{NaOH}-20$ (D)

Também podem estar associadas com as vibrações $\mathrm{OH}$ fora do plano. O grupo de bandas $\approx 1508 \mathrm{~cm}^{-1}, \approx 1458 \mathrm{~cm}^{-1} \mathrm{e} \approx 1420$ $\mathrm{cm}^{-1}$ indica vibrações associadas com deformações angulares das ligações $\mathrm{C}=\mathrm{O}$ e $\mathrm{O}-\mathrm{H}$, que correspondem a deformações axiais em ácidos carboxílicos presentes na lignina. A maioria dessas bandas é encontrada em todas as amostras, o que pode ser explicado pela lignina existente nas camadas internas da fibra de coco, não diretamente exposta às soluções alcalinas.

A banda $\approx 1375 \mathrm{~cm}^{-1}$ mostra as vibrações das ligações de hidrogênio $\mathrm{O}-\mathrm{H}$ características de compostos de taninos e dímeros de ácidos carboxílicos presentes na lignina. Esta banda aparece apenas na Figura 10A indicando que as demais amostras perderam tais ligações; por outro lado, a banda 1266 $\mathrm{cm}^{-1}$ corresponde ao grande número de grupos carbonilas $(\mathrm{C}=\mathrm{O})$ típicos para arilos- $\mathrm{O}-\mathrm{CH}_{2}$ presentes na lignina das fibras de coco. Este pico não foi observado nas amostras mais alcalinas Cimento-15 e NaOH-20 (Figura 10B e 10D), o que também pode constituir outra evidência da degradação da lignina presente na fibra; além disto a amostra mais alcalina $\mathrm{NaOH}-20$ é a única a não conter as bandas $\approx 1050 \mathrm{~cm}^{-1} \mathrm{e} \approx 1076$ $\mathrm{cm}^{-1}$, que indicam deformação axial de ligações $\mathrm{C}$-O de anel heterocíclicos presentes nos taninos condensados ou arilos-O$\mathrm{CH}_{2}$ nas moléculas de lignina. Este fato evidencia, mais uma vez, que o aumento da alcalinidade provoca uma velocidade maior de degradação da fibra de coco.

Jhon et al. (2005) afirmam que a deslignificação (perda percentual de lignina) entre fibras de coco novas, com $48 \%$ de lignina em relação às fibras degradadas após 12 anos dentro de paineis de parede, pode chegar a $14 \%$, deixando essas fibras com cerca de $34 \%$ de lignina após este longo período. O aspecto visual dessas fibras degradadas, verificado através de MEV, se assemelha às imagens obtidas pela amostra Cimento-15, ou seja, a degradação, em ambos os casos, não alcançou o estágio de desfibrilação observado nas amostras $\mathrm{NaOH}-10$ e NaOH-20 porém a perda de massa final (correspondente à camada de cutícula, partículas globulares e lignina) da amostra Cimento-15 foi de apenas 9,5\%, indicando que o ataque desta amostra foi inferior ao estudado por Jhon et al. (2005).

Considerando, no entanto, que a perda de massa final da amostra NaOH-01 (Figura 10C) foi de aproximadamente 28\% a matriz aglomerante utilizada para construir a parede era de baixa natureza alcalina (deslignificação inferior ao cimento Portland) e a imagem obtida por MEV desta amostra configura um estágio de degradação intermediário entre as amostras Cimento-15 e NaOH-10; supõe-se que a amostra NaOH-01, na condição testada pode simular, parcialmente, o processo de degradação da fibra de coco que ocorre em compósitos cimentícios a longo prazo (entre 10 - 15 anos).

\section{Conclusões}

1. De acordo com o aumento da concentração das soluções alcalinas e do tempo de contato com as fibras de coco, verificase uma modificação maior da superfície da fibra através da retirada dos constituintes superficiais, como cutículas, partículas globulares, cavidades e também lignina.

2. A amostra NaOH-20 sofreu uma degradação acentuada em um período relativamente pequeno de tempo em relação à degradação das fibras de coco presentes em matrizes cimentícias. Nesta condição o ensaio de gravimetria indicou $67,95 \%$ de perda de massa das fibras de coco em relação à massa inicial e a microscopia revelou que a superfície da fibra 
apresentou desfibrilamento. Os espectros UV e FTIR desta amostra indicaram a degradação da lignina da fibra de coco.

3. A fibra de coco imersa na solução NaOH-01 $(01 \mathrm{gNaOH}$ - 59 $\mathrm{gH}_{2} \mathrm{O}$ ), por 81 dias nas condições testadas, poderia simular o processo de degradação que se desenvolve em compósitos cimentícios a longo prazo.

\section{Agradecimentos}

Os autores agradecem às instituições públicas: IFBA, FAPESB e UESC, assim como à empresa fornecedora das fibras de coco para a pesquisa - Coque Fibras Ltda.

\section{Literatura Citada}

Agopyan, V:; Savastano Júnior, H. Cinzas e aglomerantes alternativos. In: Freire, W. J; Beraldo, A. L. (Coordenadores) Tecnologias e materiais alternativos de construção. Campinas: UNICAMP, 2003. 331p.

Albinante, S. R.; Pacheco, E. B. A. V.; Visconte, L. L. Y. Revisão dos tratamentos químicos da fibra natural para mistura com poliolefinas. Química Nova, v.36, p.114-122, 2013. http://dx.doi. org/10.1590/S0100-40422013000100021

Ali, M.; Li, Xiaoyang; Chouw, N. Experimental investigations on bond strength between coconut fibre and concrete. Materials and Design, v.44, p.596-605, 2013. http://dx.doi.org/10.1016/j. matdes.2012.08.038

Ali, M.; Liu, A; Sou, H.; Chouw, N. Mechanical and dynamic properties of coconut fibre reinforced concrete. Construction and Building Materials, v.30, p.814-825, 2012. http://dx.doi. org/10.1016/j.conbuildmat.2011.12.068

Esmeraldo, M. A.; Barreto, A. C. H.; Freitas, J. E. B.; Fechine, P. B. A.; Sombra, A. S. B.; Corradini, E.; Mele, G. Maffezzoli, A.; Mazzeto, S. E. Dwarf-green coconut fibers: a versatile natural renewable raw bioresource. Treatment, Morphology and Physicochemical Properties, v.5, p.2478-2501, 2010.

$\mathrm{Gu}, \mathrm{H}$. Tensile behaviours of the coir fibre and related composites after $\mathrm{NaOH}$ treatment. Materials and Design, v.30, p.3931-3939, 2009. http://dx.doi.org/10.1016/j.matdes.2009.01.035

Gunasekaran, K.; Kumar, P. S.; Lakshmipath, M. Mechanical and bond properties of coconut shell concrete. Construction and Building Materials, v.25, p.92-98, 2011. http://dx.doi.org/10.1016/j. conbuildmat.2010.06.053

IBGE - Instituto Brasileiro de Geografia e Estatística. Levantamento sistemático da produção agrícola. Rio de Janeiro: IBGE, v.29, 2015. 83p.

Jhon, V. M.; Cincotto, M. A.; Sjostrom, C.; Agopyan, V.; Oliveira, C. T. A. Durability of slag mortar reinforced with coconut fibre. Cement \& Concrete Composites, v.27, p.565-574, 2005. http:// dx.doi.org/10.1016/j.cemconcomp.2004.09.007

Li, X.; Tabil, L. G.; Panigrahi, S. Chemical treatments of natural fiber for use in natural fiber-reinforced composites: A review. Journal of Polymers and the Environment, v.15, p.25-33, 2007. http:// dx.doi.org/10.1007/s10924-006-0042-3
Luzardo, F. H. M.; Velasco, F. G.; Alves, C. P.; Correia, I. K. S.; Cazorla, L. L. Chemical characterization of agroforestry solid residues aiming its utilization as adsorbents for metals in water. Revista Brasileira de Engenharia Agrícola e Ambiental, v.19, p.77-83, 2015. http://dx.doi.org/10.1590/1807-1929/agriambi. v19n1p77-83

Nam, T. H.; Ogihara, S.; Tung, N. H.; Kobayashi, S. Effect of alkali treatment on interfacial and mechanical properties of coir fiber reinforced poly (butylene succinate) biodegradable composites. Composites Part B: Engineering, v.42, p.1648-1656, 2011. http:// dx.doi.org/10.1016/j.compositesb.2011.04.001

Ramakrishna G.; Sundararajan T. Studies on the durability of natural fibres and the effect of corroded fibres on the strength of mortar. Cement \& Concrete Composites, v.27, p.575-582, 2005. http:// dx.doi.org/10.1016/j.cemconcomp.2004.09.008

Ramírez, M. G. L. R. Desenvolvimento de biocompósitos de amido termoplástico reforçados por fibra de coco verde. Curitiba: UFPR 2011. 148. Tese Doutorado

Ramli, M.; Kwan, W. H.; Abas, N, F, Strength and durability of coconut-fiber-reinforced concrete in aggressive environments. Construction and Building Materials, v.38, p.554-566, 2013. http:// dx.doi.org/10.1016/j.conbuildmat.2012.09.002

Rodríguez, N. J.; Limón, M. Y.; Miceli, F. A.; Gusman, O. G.; Ortiz, T. P. M.; Rivera, L. L.; Feijoo, J. A. V. Assessment of coconut fibre insulation characteristics and its use to modulate temperatures in concrete slabs with the aid of a finite element methodology. Energy and Buildings, v.43, p.1264-1272, 2011. http://dx.doi. org/10.1016/j.enbuild.2011.01.005

Salmah, H.; Marliza, M.; Teh, P. H. Treated coconut shell reinforced unsaturated polyester composites. International Journal of Engineering \& Technology, v.13, p.94-103, 2013.

Savastano Júnior, H; Agopyan, V. Transition zone studies of vegetable fibre-cement paste composites. Cement \& Concrete Composites, v.21, p.49-57, 1999. http://dx.doi.org/10.1016/S09589465(98)00038-9

Saw, S. K.; Sarkhel, G.; Choudhury, A. Surface modification of coir fibre involving oxidation of lignins followed by reaction with furfuryl alcohol: Characterization and stability. Applied Surfece Science, v.257, p.3763-3769, 2011. http://dx.doi.org/10.1016/j. apsusc.2010.11.136

Silva, E. J.; Marques, M. L.; Fornari Júnior, C. Aplicação de fibra de coco em matrizes cimentícias. Revista Eletrônica em Gestão, Educação e Tecnologia Ambiental, v.8, p.1555-1561, 2012.

Silva, E. J.; Silva, P. D.; Marques, M. L.; Fornari Júnior, C. C. M.; Velasco, F. G.; Luzardo, F. M. Resistência à compressão da argamassa em função da adição de fibra de coco. Revista Brasileira de Engenharia Agrícola e Ambiental, v.18, p.1268-1273, 2014. http://dx.doi. org/10.1590/1807-1929/agriambi.v18n12p1268-1273

Toledo Filho, R. D.; England, G. L.; Ghavami, K. Comportamento em compressão de argamassas reforçadas com fibras naturais. Revista Brasileira de Engenharia Agrícola Ambiental, v.1, p.79-88, 1997.

Toledo Filho, R. D.; Scrivener, K.; England, G. L.; Ghavami, K. Durability of alkali-sensitive sisal and coconut fibres in cement mortar composites. Cement \& Concrete Composites, v.22, p.127143, 2000. http://dx.doi.org/10.1016/S0958-9465(99)00039-6 